he means in a broad sense. He argues that any emergent technology requires many players, not just an inventor with a great idea. There is a field of players involved in negotiations and development, and only some of the resulting technologies are ultimately successful. This plays back into the problem of predictability.

What's missing from Nye's account - and this is a complaint that can be levelled at 'social constructionists' - is a sensitivity to the 'materiality' of technologies. Part of the struggle is not just that of markets, social structure and the like, but also the resistance and accommodation of the material used. For example, consider human powered flight. Most of Leonardo da Vinci's machines would have failed to fly because of their sheer weight and lack of strength. But when the Gossamer Albatross was constructed in 1979 using modern materials, kevlar and mylar, it was moderately successful. One exception for Leonardo, according to a recent account (see Nature 421, 792; 2003), was a glider, but this was modified by subtracting heavy control mechanisms and adding hang-glider strengtheners.

Nye's book addresses many of the issues and debates surrounding our highly textured technological society, and these are reflected in the questions he asks. Does technology control us? Does it lead to cultural uniformity or diversity? To sustainable abundance or to ecological crisis? To more security or escalating danger? The book is rich in examples, is easily readable and is short enough to be recommended for a day's read.

Don Ihde is in the Department of Philosophy, Stony Brook University, Stony Brook,

New York 11794, USA.

\title{
On fertile ground
}

\section{Soils and Societies: Perspectives from Environmental History edited by J. R. McNeill \& \\ Verena Winiwater \\ White Horse Press. 2006. 369 pp. $£ 50$}

\section{Camilla Toulmin}

Soil is often viewed as just 'dirt', but Soils and Societies, edited by J. R. McNeill and Verena Winiwater, shows why soil provides the foundation on which our societies are based. Soil enters ordinary speech in many and various ways. We talk of seed falling on fertile ground, and the transformation wrought by rain falling on parched soils. Long-time urban dwellers wait for years for their name to top the list for a small allotment to grow fruit and vegetables. In Marcel Pagnol's novel Jean de Florette, the central characters taste the soil of a field they hope to acquire to get an indication of its quality - a practice dating back, so Soils and Societies tells us, to Roman times and before.

Western society today is particularly disconnected from farming life, leading to contradictory demands on what we want the food and agricultural system to do for us. So this book is a valuable reminder of the former close understanding of the soil that human societies needed to harvest higher returns and maintain soil structure and quality. A delight for the soil aficionado, this book teases out multiple threads from different societies and weaves them together to show how the fabric of daily life is closely connected to the soils from which their bread has been harvested.

Eleven chapters range from a discussion of early Indian poetry about the natural world and a history of the soils of Mesoamerica to a discussion of nutrient flows in pre-modern European agriculture. The chapter on the dynamics of soil, landscape and culture on Easter Island provides welcome clarity on how and why this extraordinary culture, known for its massive stone sculptures of heads, came to an end.

In the introductory chapter, the editors provide a valuable framing of the main issues. Ultimately we all depend on the continued health of certain fundamental ecosystem elements and processes. As the Millennium Ecosystem Assessment reported last year, the health of our soils, in wetlands, forest areas and dry savannas, is declining. Soils have their own histories, natural and human, which intertwine, leading either to declining productivity or, if they are well managed, to sustaining the heart of the farming system.

Soils change in different ways, depending on the time scale. Gully erosion can open up a hillside in a few hours after an exceptional storm. Over decades, the barely noticeable losses each year from sheet erosion cumulatively bring about a scarred landscape, like skin drawn too tight over a bony visage. The sediment found in lake beds forms a rich archive of information about former patterns of vegetation, land use and climatic changes.

Given my own background in west Africa and work on the interaction between crops and livestock, I particularly enjoyed the chapter on African soils. It presents well the different assumptions brought to sub-Saharan Africa by colonial administrators, and their everready desire to transplant foreign agricultural knowledge into local farming systems. And despite occasional massive failures with such enterprises, such as the groundnut scheme in Tanganyika in the 1940s and 50s, the power of the narrative linking African peasant farmers to poor soil management has enabled confidence among the soil experts to be sustained even today. As the book points out, "theory moulds perceptions of environmental change", made worse by the lack of detailed data on which to make firm judgements. Yet soil scientists are slowly starting to break free from conventional approaches to soil and water conservation and turn to more participatory methods that recognize local knowledge and expertise. These are now bearing a harvest of their own, even in areas with low rainfall such as the West African Sahel, with the spread of simple methods for catching rainfall and concentrating both water and organic matter along with the seed in small planting pots.

Thankfully, the past five years have seen a massive growth in demand for organic food, bringing a return to the kind of knowledge and understanding among farmers about what works best for the diverse contexts and constraints faced in different parts of the farm landscape. With luck, the rising cost of oil and energy will also help shift farm production away from high-intensity inputs and mechanization towards the greater use of agroecological processes. It's good to know that in this book and its detailed reference list there lies a sound body of historical material on soils that has been laid down over time.

Camilla Toulmin is director of the International Institute for Environment and Development, 3 Endsleigh Street, London WC1H ODD, UK.

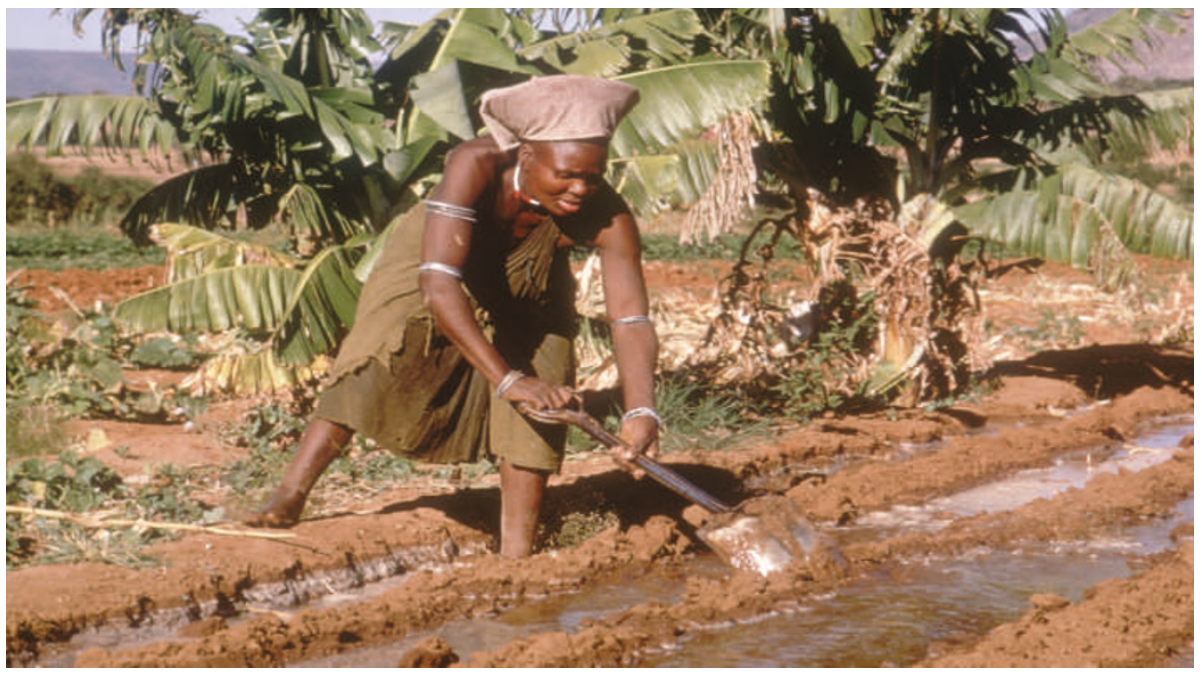

Laying the groundwork: growing crops in areas with low rainfall requires good soil management. 